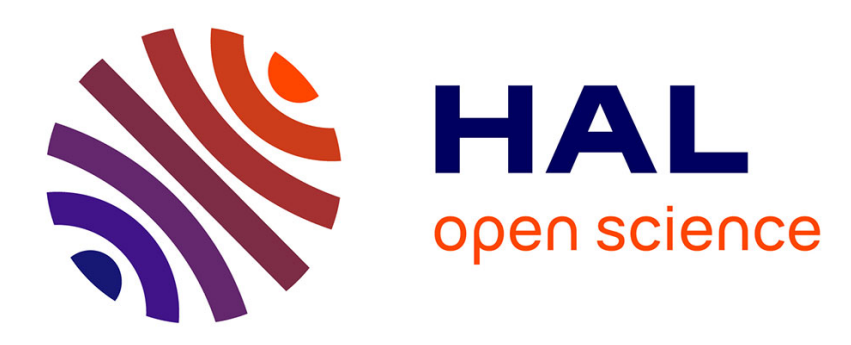

\title{
Regional Technology Development Path in an Open Developing Economy: Evidence from China
}

\author{
Tieli Li, Miao Fu, Xiaolan Fu
}

\section{To cite this version:}

Tieli Li, Miao Fu, Xiaolan Fu. Regional Technology Development Path in an Open Developing Economy: Evidence from China. Applied Economics, 2011, 45 (11), pp.1405-1418. 10.1080/00036846.2011.617701 . hal-00768583

\section{HAL Id: hal-00768583 \\ https://hal.science/hal-00768583}

Submitted on 22 Dec 2012

HAL is a multi-disciplinary open access archive for the deposit and dissemination of scientific research documents, whether they are published or not. The documents may come from teaching and research institutions in France or abroad, or from public or private research centers.
L'archive ouverte pluridisciplinaire HAL, est destinée au dépôt et à la diffusion de documents scientifiques de niveau recherche, publiés ou non, émanant des établissements d'enseignement et de recherche français ou étrangers, des laboratoires publics ou privés. 


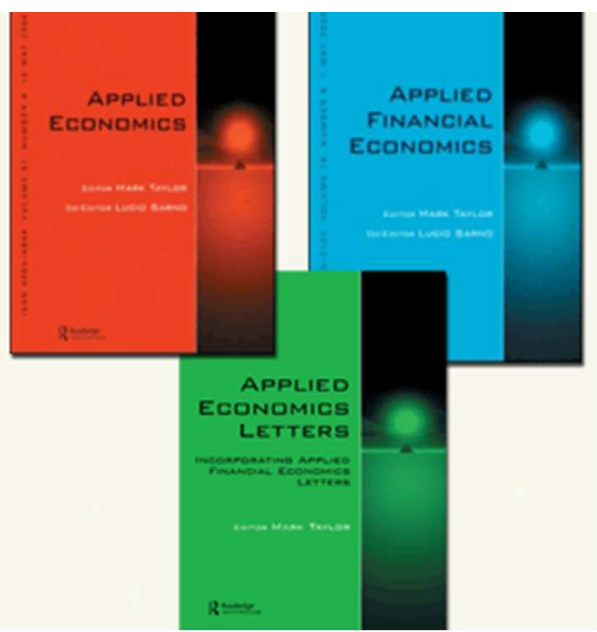

\section{Regional Technology Development Path in an Open Developing Economy: Evidence from China}

\begin{tabular}{|r|l|}
\hline Journal: & Applied Economics \\
\hline Manuscript ID: & APE-2010-0335.R1 \\
\hline Journal Selection: & Applied Economics \\
\hline Author: Submitted by the & 03-Apr-2011 \\
\hline Complete List of Authors: & $\begin{array}{l}\text { Li, Tieli; Guangdong University of Foreign Studies } \\
\text { Fu, Mia; University College Dublin } \\
\text { Fu, Xiaolan; Oxford University, Dept of International Development }\end{array}$ \\
\hline JEL Code: & $\begin{array}{l}\text { F21 - International Investment|Long-Term Capital Movements < F2 - } \\
\text { International Factor Movements and International Business < F - } \\
\text { International Economics, D24 - Production|Capital and Total Factor } \\
\text { Productivity|Capacity < D2 - Production and Organizations < D - } \\
\text { Microeconomics, O33 - Technological Change: Choices and } \\
\text { Consequences|Diffusion Processes < O3 - Technological Change|Research } \\
\text { and Development < O - Economic Development, Technological Change, } \\
\text { and Growth, O14 - Industrialization; Manufacturing; Service Industries; } \\
\text { Tech Choice < O1 - Economic Development < O - Economic } \\
\text { Development, Technological Change, and Growth }\end{array}$ \\
\hline Keywords: & $\begin{array}{l}\text { technology transfer , learning by doing , FDI, regional technology } \\
\text { development }\end{array}$ \\
\hline & \multicolumn{2}{|l}{} \\
\hline
\end{tabular}




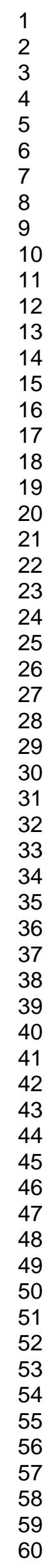

14

15

16

18

19

20

22

23

25

26

27

29

30

32

33

34

35

36

37

38

41

42

43

45

46

47

48

49

51

52

53

54

56

57

58

60

Editorial Office, Dept of Economics, Warwick University, Coventry CV4 7AL, UK 


\title{
Regional Technology Development Path in an Open Developing Economy: Evidence from China
}

\begin{abstract}
This paper explores the paths of regional technology development in a large open developing economy. Findings from the research based on Chinese data suggest a differentiated approach to regional technology development. In technologically advanced regions, indigenous R\&D plays a more important role than learning by doing while in backward regions the latter becomes more important. Interregional technology transfer is found to have a more significant impact on regional technology development than foreign direct investment and its effect intensifies when the technology level of the recipient region is close to the technological frontier. R\&D plays a key role in both the assimilation of foreign technologies in advanced regions and the assimilation of interregional technology transfer; learning by doing only affects the latter.
\end{abstract}

Keywords: technology transfer, learning by doing, FDI, regional technology development JEL code: D24, F21, O3, O1 


\section{Introduction}

Technical progress is an important driver of economic growth. For developing countries, one of the questions that has attracted substantial debate is whether these nations should rely on technology transfers from advanced countries or rather rely on independent innovation to further the development of technology. Many studies have addressed the technology transfer effects of foreign direct investment (FDI). Most of these studies argue that technology transferred from developed countries through FDI has positive effects on developing countries (Eden et al., 1997; Kokko et al., 1997).1 However, the literature on 'appropriate technology' suggests that technologies developed in industrialised countries are not appropriate for developing countries whose factor endowments and socio-economic conditions are significantly different from those in developed economies (Atkinson and Stiglitz, 1969; Acemoglu, 2002). Fu and Gong (2011) find that indigenous technology is more efficient than foreign technology in the low- and medium-technology intensive industries in China. For developing countries where economic and technology levels differ across regions, a pertinent question to explore is whether the regions should all 'race-to-the-bottom' in technology. A second issue is to examine the role of foreign and indigenous technology and learning-by-doing in different regions. New technologies can be transferred from advanced domestic regions to less advanced ones through competition, upstream or downstream association, flows of human resources and imitation of new

1 Eden, Lecitas and Martinez (1997) conclude that there are four ways in which technology transfer from FDI to the host can occur: (i) domestic enterprises copy or imitate technology and management mechanisms of foreign enterprises, (ii) develop upstream or downstream associations with foreign firms, (iii) employ personnel that have been trained by the latter, or (iv) they compete with foreign enterprises in the market. 
products and management mechanisms. Cross regional technology transfer can be an important force for regional technological development. Therefore, to develop an in-depth understanding of technological progress, it is important to consider both international and intra-national technology transfer: that is, to consider the 'bi-channel technology transfer' from FDI and from technologically advanced domestic regions.

The existing literature related to bi-channel technology transfer is mainly centred on developed countries. For instance, Brendstetter (2001) finds that, in the case of the US and Japan, intra-national knowledge spillovers are more important as a source of technological progress than international spillovers. However, we lack empirical studies of bi-channel technology transfer that focus on developing countries: most works somewhat neglect technology transfer among indigenous regions within these nations.

This paper presents a regional technological development model incorporating internal and external factors which provide two routes to technological development in developing countries. Technology transfer via FDI constitutes the external route through which advanced foreign technology may be transferred to the host country. The internal channels for technological progress include cross regional technology transfer from advanced regions, R\&D and learning by doing. Literature has identified that FDI, R\&D, absorptive capacity have each contributed significantly to regional capability for innovation (eg., Ivarsson, 2002; Porter et al. 2002; Fu, 2008). However, the role of cross regional transfer of technology has not been fully explored especially in the context that technology capabilities and development levels of the regions are substantially different. The framework is empirically tested with 


\section{Theoretical Framework}

This section sets out the theoretical framework of the paper, taking into account R\&D and learning by doing, as well as international and intra-national technology transfer. Two opposing perspectives exist with regard to the choice of technological development paths for developing countries. One stream of literature argues that the technology transfer effects of FDI may be more important than the effects of domestic investments (Borensztein et al., 1995) whilst Findlay (1978) finds that the technology diffusion capacity of FDI increases as the technology distance between the host and foreign countries increases. ${ }^{2}$ Moreover, given the need for large amounts of investment and the high risks involved with innovation, the

2 Some authors do not agree with this perspective. For instance, Kokko et al. (1997) finds positive and significant spillover effects only when the technological gap is moderate or small. 
developing countries are unable to complete the entire process of innovation independently (Erdilek, 1984; Hoekman et al., 2004).

On the other hand, the introduction of FDI will make competing domestic firms worse off (Aitken and Harrison, 1999) and will reduce their R\&D efforts (OECD, 2002). The benefits of FDI technology transfer are limited because most techniques transferred from foreign-funded firms are usually mature rather than frontier techniques. Thus, as the working conditions and rewards offered by overseas-funded firms are better than those of native firms, knowledge diffusion caused by the turnover of local talented personnel usually takes place in one direction: from domestic firms to foreign-funded ones. Considering that technological progress has path dependent characteristics, a country that depends on technology transfer from FDI for a long period of time is likely to have limited capabilities for independent innovation. In reality, most developing countries do not separate the internal and external routes to achieving technological progress. Neither autonomous innovations nor FDI-reliant strategies can be used independently (Lall, 2004).

Following Cameron et al. (2005), we start from a production function presented in Equation (1), where the region is denoted by $i$ and time by $t$. We use $Y_{i, t}$ to represent the value added output of region $i$ in period $t$, produced with labour $L_{i, t}$ and capital stock $K_{i, t}$. Further, $A_{i, t}$ stands for technical progress and technical efficiency, or total factor productivity. We assume that the $A_{i, t}$ of different regions and time are variable.

$$
Y_{i, t}=A_{i, t} K_{i, t}{ }^{\alpha} L_{i, t}{ }^{\beta}
$$


In Equation (1), we assume that technical progress $A_{i, t}$ can be acquired through four routes: learning by doing, $\mathrm{R} \& \mathrm{D}$, technology transfers from other regions and technology transfers from FDI. The first three routes are given emphasis in the perspective that supports an independent path for technical progress, while the last route constitutes the core of a perspective based on dependent paths which require technologies to be transferred from external sources. The basis for grouping together learning by doing and R\&D is the theory developed by Young (1993), who argues that these routes are inseparable. According to this understanding, scientific studies help invent new goods whilst the learning by doing strategy leads to the development of such new goods into mature products. Without scientific research, learning by doing seldom brings about innovation, given that the economy continues to produce the same goods. Alternatively, without learning by doing, the newly invented goods are not improved through practice, and therefore remain in the initial deficient stages, unable to replace old mature products. This leads to the failure of new goods in markets and causes shrinkages in subsequent R\&D.

With respect to technology transfer between domestic provinces, following convergence theories (Barro and Sala-i-Martin, 1995) and technology gap theories (Findlay, 1978; Fagerberg, 1994), we assume that potential of technology transfer is related to technology distance. Following Caniëls and Verspagen (1999), we represent the relationship between technology transfer and interregional technology distance using Equation (2), where $\phi_{i j, t}$ represents the degree of technology transfers existing between regions $i$ and $j$ in period $t$, and $D_{i j, t}$ denotes the technology distance between regions $i$ and $j$. Caniëls and Verspagen (1999) regard $\rho$ and $\mu$ as parameters that are related to intrinsic learning capability, while assuming $\rho$ 
$<0$ and without considering the effects of technology thresholds. Here we view $\mu$ as the threshold value or the turning point of the relationship and $\rho$ as the test coefficient for cross-regional technology transfers. The value of $\rho$ can be smaller, greater or equal to zero. $\lambda_{i}$ stands for initial endowed technological absorptive capacity which is constant in region $i$.

$$
\phi_{i j, t}=\lambda_{i} e^{\rho\left(D_{i j, t}-\mu\right)^{2}}
$$

Following Cameron et al. (2005) and Griffith et al. (2004), we utilise the logarithm of the ratio produced by TFP of the technological frontier divided by the TFP of the relevant region to proxy inter-regional technology transfer $\left(D_{i j, t}\right)$, which is greater than or equal to zero. When $\rho<0$ and $D_{i j, t}$ is less than the threshold value, the degree of technology transfer increases as technology distance increases. Alternatively, if $D_{i j, t}$ is greater than the threshold value, then the degree of technology transfer diminishes as technology distance increases. $\rho<$ 0 means that the threshold is the optimized distance to maximize technology transfer. When $\rho$ $>0$ and the value of $D_{i j, t}$ is lower than the threshold, the smaller the technology distance, the greater are the technology transfers. However, if $D_{i j, t}$ is higher than the threshold, an increase in technology distance corresponds to a rise in technology transfers. $\rho>0$ indicates that the threshold is the worst point for technology transfer, and if a region surpasses this threshold, it will get increasing return of technology transfer.

Some authors (e.g., Girma, 2005) find that there is a discontinuous change in the technology transfer effects of FDI around the threshold value. That is, when technology distance surpasses such a level, technology transfer will change from insignificant to significant, with its impact switching from positive to negative externalities. In our study, Equation (2) is used 
to measure cross-regional technology transfers. The technological gap between provinces is not wide enough to bring about discontinuous effects such as a sudden stop in technology transfers, nor cause any splitting of the sample. Therefore, we assume that there is no discontinuous change around the threshold value so that the technology transfer curve continues, although there is a change in trend after the threshold value. In other words, in our case the threshold is the turning point of the curve, not the splitting point of the sample.

We assume that learning by doing influences TFP immediately but that the influence of R\&D upon TFP involves a one year time lag. We also assume that cross regional technology transfers experience a one-year lag. This lag is based on the results of Mansfield (1985), who finds that 70 per cent of new innovations 'leak out' within one year. According to the above analysis, we hypothesize $A$ to be a function of learning by doing, $R \& D$, technology transfers from FDI and technology transfers from other regions:

$$
A_{i, t}=B_{i} K_{i, t}^{\alpha} R_{i, t-1}^{\beta} F_{i, t}^{\gamma} \lambda_{i} e^{\rho\left(\ln \frac{A_{j, t-1}}{A_{i, t-1}}-\mu\right)^{2}}
$$

where $A_{i, t}$ stands for TFP, representing technological progress of region $i$ in period $t ; R_{i, t-1}$ is the R\&D capital stock of region $i$ in period $t-1, F_{i, t}$ stands for FDI stock in region $i$ in period $t$. $A_{j, t-1}$ is the TFP of the technological frontier, $A_{i, t-1}$ is the TFP of the area that is currently under study. The last term denotes the degree of cross-regional transfers of techniques.

There are two ways for the measurement of learning by doing. Arrow (1962) and Jovanovic (1995) suggest that technological learning is a major mechanism for technology diffusion and 
most of learning taking place through "learning by investment". Therefore, capital stock is representative of learning by doing. Another body of work uses output as a proxy of learning by doing (eg., Caniëls and Verspagen, 1999). The Verdoorn-Kaldor law states that a positive relation exists between the growth of productivity and the growth of output. Output growth is thus a major mechanism for learning by doing. Yet comparing the two variables, output reflects only the current year's production activities, while capital stock records the contributions of cumulative historic capital investment. Therefore, following Arrow (1962) and Jovanovik (1995), we use capital stock $\left(K_{i, t}\right)$ instead of output to represent cumulative learning by doing experience. We take $\alpha$ to denote the output elasticity of learning by doing.

We do not limit the output elasticity of each input factor, nor assume constant returns to scale since knowledge can be repeated at low cost. Merging $\lambda_{\mathrm{i}}$ into $B_{\mathrm{i}}$ and taking logarithms on both sides of Equation (3), we arrive at:

$$
\begin{aligned}
& \ln \left(A_{i, t}\right)=\ln \left(B_{i} \lambda_{i}\right)+\alpha \ln \left(K_{i, t}\right)+\beta \ln \left(R_{i, t-1}\right)+\gamma \ln \left(F_{i, t}\right)+\rho\left[\ln \left(\frac{A_{j, t-1}}{A_{i, t-1}}\right)-\mu\right]^{2} \\
& \text { where } \ldots \rho\left[\ln \left(\frac{A_{j, t-1}}{A_{i, t-1}}\right)-\mu\right]^{2}=\rho \ln ^{2}\left(\frac{A_{j, t-1}}{A_{i, t-1}}\right)-2 \rho \mu \ln \left(\frac{A_{j, t-1}}{A_{i, t-1}}\right)+\rho \mu^{2}
\end{aligned}
$$

In Equation (4), the technology distance term and its square, that is, $\ln \left(A_{j, t-1} / A_{i, t-1}\right)$ and $\ln ^{2}\left(A_{j, t-1} / A_{i, t-1}\right)$, are used to measure the contribution of cross regional technology transfers. Following Cameron et al. (2005) and Griffith et al. (2004), technology transfer is measured by the linear or interaction term of $\ln \left(A_{j, t-1} / A_{i, t-1}\right)$. In addition to the linear term, we include its quadratic term to estimate the non-linear relationship between technology distance and technology transfer. If $\rho=0$, this means that cross regional technology transfer is nonexistent. 
Alternatively, if $\rho<0$ or $\rho>0$, there is the turning relationship between technology distance and technology transfer we discussed in Equation (2). Merging the constants together, and using a random variable $\varepsilon$ to represent the effect of any further factors that are not included in the model, we get the econometric form of Equation (4):

$$
\ln \left(A_{i, t}\right)=C_{i}+\alpha \ln \left(K_{i, t}\right)+\beta \ln \left(R_{i, t-1}\right)+\gamma \ln \left(F_{i, t}\right)+\rho \ln ^{2}\left(\frac{A_{j, t-1}}{A_{i, t-1}}\right)+\varphi \ln \left(\frac{A_{j, t-1}}{A_{i, t-1}}\right)+\varepsilon_{i t}
$$

The estimated values of $\varphi$ and $\rho$ can be used to calculate the threshold value $\mu$ with the formulation $\mu=\varphi /(-2 \rho)$. In turn, $\beta$ is used to measure the impact of $\mathrm{R} \& \mathrm{D}$ on independent innovation. Considering innovative and imitative aspects of $R \& D$ activities, the $R \& D$ efforts of region $i$ not only improve its technical creative ability directly and increase TFP but also indirectly raise the area's absorptive abilities vis-à-vis advanced technology transferred from other regions or through FDI. Therefore, we use the interaction term of R\&D and technology distance, which represents the absorptive capacity of $R \& D$ with regard to cross-regional technology transfers, as well as the interaction term of R\&D and FDI, which stands for the absorptive capacity of $\mathrm{R} \& \mathrm{D}$ in relation to FDI technology transfers. The corresponding econometric specification is represented by Equation (6):

$$
\begin{aligned}
\ln \left(A_{i, t}\right)= & C_{i}+\alpha \ln \left(K_{i, t}\right)+\beta \ln \left(R_{i, t-1}\right)+\gamma \ln \left(F_{i, t}\right)+\rho \ln ^{2}\left(\frac{A_{j, t-1}}{A_{i, t-1}}\right)+ \\
& \varphi \ln \left(\frac{A_{j, t-1}}{A_{i, t-1}}\right)+\theta_{1} \ln \left(F_{i, t}\right) \ln \left(R_{i, t-1}\right)+\theta_{2} \ln \left(\frac{A_{j, t-1}}{A_{i, t-1}}\right) \ln \left(R_{i, t-1}\right)+\varepsilon_{i t}
\end{aligned}
$$


In the equation above, $\theta_{1}$ measures the absorptive ability of $\mathrm{R} \& \mathrm{D}$ in relation to FDI technology transfers, and $\theta_{2}$ measures its capacity to absorb technology transfers from the native technological frontier.

Learning by doing comprises the ability to absorb foreign technology other than R\&D. In this paper, we also use the interaction term of the logarithm of learning by doing capital stock and technology distance and FDI to represent learning by doing abilities to assimilate cross regional technology transfers and foreign technology transfers. The econometric specification is shown in Equation (7). The absorptive effects of the two channels above are captured by the coefficients of $\theta_{4}$ and $\theta_{3}$, respectively. To capture the pure effects of learning by doing and avoid the including the contents of $R \& D$ in learning by doing, we subtract $R \& D$ stock from the calculation of $K_{i, t}$.

$$
\begin{array}{r}
\ln \left(A_{i, t}\right)=C_{i}+\alpha \ln \left(K_{i, t}\right)+\beta \ln \left(R_{i, t-1}\right)+\gamma \ln \left(F_{i, t}\right)+\rho \ln ^{2}\left(\frac{A_{j, t-1}}{A_{i, t-1}}\right)+ \\
\varphi \ln \left(\frac{A_{j, t-1}}{A_{i, t-1}}\right)+\theta_{3} \ln \left(F_{i, t}\right) \ln \left(K_{i, t}\right)+\theta_{4} \ln \left(\frac{A_{j, t-1}}{A_{i, t-1}}\right) \ln \left(K_{i, t}\right)+\varepsilon_{i t}
\end{array}
$$

As stated earlier, industries in technologically backward areas receive technology transfer not only from local FDI but also from technologically advanced native regions. This, in our paper, is referred to as 'bi-channel technology transfer' and the crux of our analysis consists in determining which of these channels is more important, what characteristics these two routes have, and whether the transferred technologies are absorbed through R\&D or through learning by doing. Following the model outlined above, we present the following hypotheses: 
H1. Learning by doing has positive effects on technological progress represented by the coefficient $\alpha$ in Equations (5), (6), and (7), which is thus positive.

H2. The independent innovative abilities of R\&D contribute positively to the TFP of a region, represented by the coefficient $\beta$ in Equations (5), (6), and (7), which is therefore positive.

H3. When the FDI stock increases, the technology transfer from FDI also increases. This is represented by the technology transfer coefficients $\gamma$ in Equations (5), (6), and (7).

Where the technological levels of two regions are close, the opportunity for study and imitation decreases (Fagerberg, 1994; Caniëls and Verspagen, 1999). Thus, with an increase in the technological gap, the possibility of technology transfers also initially rises. However, the technological gap should not be too wide either. According to technological gap theories, if such a distance is too great, then the backward region is unable to absorb the transferred technologies even if the capacity for study and imitation grows, owing to the lack of knowledge stock and qualified human resources. Therefore, after the technology distance surpasses a specific threshold value, the possibility of technology transfers occurring decreases. Hence we have the following hypothesis:

H4. Both cross regional technology transfers and the threshold of cross regional technology transfers exist. The technology transfer effect first rises with technology distance, but declines once it surpasses the threshold value. That is, we assume that $\rho<0$ and $\varphi>0$, and this also implies that $\mu>0$. 
We also need to take into account the view that $R \& D$ and learning by doing affects technological growth in two ways (Griffith et al., 2004), and accordingly we have:

H5a. When the R\&D budget of a certain area increases, for a given technology distance and FDI capital stock, the absorptive capacity rises both in respect to cross regional and FDI technology transfers. This implies that the coefficients $\theta_{1}$ and $\theta_{2}$ in Equation (6) are positive.

H5b. Learning by doing also affects technological growth in two ways, so the coefficients $\theta_{3}$ and $\theta_{4}$ in Equation (7) are also positive.

We use provincial data for the years 1990 to 2006 to estimate the model. The data is collected from the China Statistical Yearbooks, and China Statistical Yearbooks on Science and Technology, both as published by the National Bureau of Statistics (NBS, various issues) from 1991 through to 2007: each edition of the Yearbooks contains data relating to the previous calendar year. All variables are in constant 1990 prices. The capital stock of each province is calculated using the perpetual inventory method: $K_{i, t}=I_{i, t}+(1-9.6 \%) K_{i, t-1}$, where 9.6 per cent is the depreciation rate of capital stock and $I_{i, t}$ is the gross capital formation of region $i$ in period $t$. The capital stock in the initial year and the depreciation rate of 9.6 per cent are taken from the data used in Zhang et al. (2004), which calculated the depreciation rate based on the weighted average of three major types of capital. Their estimates are widely accepted in China. To represent $R \& D$, we use provincial expenditure allocated to scientific and technological funds, while for FDI data we utilize the relevant provincial yearbook published from 1991 through to 2006. To calculate the FDI stock, the same perpetual 


\section{Estimation of Provincial TFP and the Technological Frontier}

In our model, TFP is the core variable in our model and it is generally taken to represent technology and efficiency, and indeed, we can understand the former as an extensive definition of the latter. TFP includes not only science and technology in their strict definition but also management efficiency internal or external to the firm, comprising, for example, efficient operating mechanisms within the company, qualified public services, a properly functioning taxation system, and the protection of property rights.

The technological frontier is represented by the province with the highest TFP, yet difficulties exist in the estimation of the latter. These include decisions related to capital stock and labour, as well as their output elasticities, since various choices with respect to these may cause notable differences in the estimation results. Zhang and Shi (2003), for instance, calculate Chinese TFP from 1952 to 1998 based on time series data for the country, and their estimation approach and results are widely accepted within Chinese academic circles. For precise results, we estimate provincial TFP based on their method, which estimates the output 
elasticities for capital stock and labour independently using the model shown in Equation (9). 3

$$
\ln Y_{i t}=C_{i}+\lambda t+\alpha \ln K_{i, t}+\beta \ln L_{i, t}+\varepsilon_{i t}
$$

Taking the output elasticities calculated above and equation (10), we construct the provincial TFP time series:

$$
A_{i, t}=\frac{Y_{i, t}}{K_{i, t}^{\alpha} L_{i, t}^{1-\alpha}}
$$

From the TFP estimation results, we can observe that the technologically advanced provinces are located in the coastal area. Guangdong is on the frontier of Chinese reform and opening-up, and its TFP is the highest for the research period. As mentioned above, TFP embodies an extensive definition of technology. The fact that Guangdong records the highest TFP value does not mean that the province has the strongest innovation abilities in China but instead that it has the best capacity for applying technologies. Invention and application are two different concepts and only applied technology can be observed in TFP. Therefore, a province that allocates a significant proportion of its budget to scientific research does not necessarily exhibit a high level of TFP. Furthermore, thanks to contact with foreign enterprises and self-endeavour, Guangdong has achieved an efficient public management system, a good business culture, and relatively strict protection of property rights. Due to the

3 When calculating TFP, we do not subtract R\&D stock from $K$, that is, it is the capital stock in general meaning. 
accumulation of human resources, technology and reforms, some traditional industrial regions also enjoyed high TFP.

According to hypothesis $\mathrm{H} 4$, one of the premises for technology transfer is the existence of technology distance among countries or regions. Since the technologically advanced provinces are mostly located in the coastal areas, we divide the different regions of China into east, central and west areas. We then calculate the average TFP for each, which we show in Panel A of Figure 1 under the labels TFPE, TFPC TFPW, corresponding to the east, central and west areas, respectively. In turn, TFPH represents the highest TFP level in China. Finally, TFPA is the average TFP for the whole country. Provincial and regional average TFPs of all years are provided in Table 1.

TFP ratios in Figure 1(B), identified as TFPED, TFPCD and TFPWD for east, central and west areas are measured such that the value of the TFP of the technology frontier is set to 1 . From these graphs, we can observe terraced structure that TFP increases gradually from west to east and that the TFP of the central area is almost equal to the TFPA. Although the average TFP of each of the three areas is increasing along time, gaps among them remain. That is, as the western regions go through technological progress, the eastern regions also advance. Therefore, with regard to technological progress, our research finds no convergence in the review of present TFP. This does not, however, entirely preclude the possibility of convergence, a possibility which is addressed in the following sections. The descriptive statistics of TFP and other variables in the model are show in Table 2. 


\section{Results}

Equations (5), (6), and (7) represent, respectively, the basic model, the R\&D interaction model, and the learning by doing interaction model. Chi-squared statistic of the Hausman test with the null hypothesis in favour of random versus fixed-effects model is 857.57 . The null hypothesis of random effects is rejected accordingly. Therefore, we employ fixed-effects models for the panel data for the estimation. The F Statistic of Redundant Fixed Effects Tests is 30.96. It also indicates that fixed effects (regional effects) are not redundant in comparison with the pooled OLS (without regional effects). The estimation results of the three models are given in Table 3. The basic model does not include interaction terms, and it measures the independent impact of each of the four routes to technological progress. After adding the interaction items, the impacts of $\mathrm{R} \& \mathrm{D}$ and learning by doing are differentiated into independent innovation effects and absorptive capacity effects.

In Table $1, K_{i, t}$ denotes the capital stock that does not include R\&D stock, $A_{j, t-1}$ represents the TFP of the technological frontier, and $A_{i, t-1}$ stands for the TFP of the region currently under study. The meanings of the remaining variables are explained in Equations (5), (6), and (7).

Table 4 shows the estimation results of the R\&D interaction model and the learning by doing interaction model, according to regions which correspond to the east, and combined central and west regions of China, respectively. Since the east part of the country is technologically advanced, the table also provides separate estimation results for the technologically advanced regions (east) and for less technologically advanced ones (central and west considered together). 


\section{Identification of technological threshold and cross-regional technology transfer}

We begin by identifying the cross regional technology transfer threshold. The coefficients of $\ln \left(A_{j, t-1} / A_{i, t-1}\right)$ and its square are all significant at the 1 per cent or 5 per cent level in the three models, as shown in Table 3 and Table 4. The fact that $\rho$ is significantly different from zero in these three models supports the notion that cross regional technology transfers exist. Since $\varphi$ is negative in the three models, $\mu$ is positive. The estimated coefficients are similar in the basic model and the R\&D interaction model.

Given that the basic model does not include interaction items, it is of a more general nature than the special models that do contain this type of term. Therefore, we calculate the threshold value $\mu$ based on the estimation results of the basic model:

$\mu=\varphi /(-2 \rho)=-1.3794 /(-2 * 0.6459)=1.0678$

The range of $\ln \left(A_{j, t-1} / A_{i, t-1}\right)$ in our observations is [0, 1.0493], which means that the threshold value 1.0678 is greater than the upper bound of the interval. Thus, so far the technology distance does not surpass the threshold value. Since $\rho>0$, such an empirical result contradicts hypothesis H4. When we draw the technology distance and technology transfer relationship curve based on the estimated coefficients, we arrive at Figure 2. The figure depicts the relevant section of the curve, considering the actual range of $\ln \left(A_{j, t-1} / A_{i, t-1}\right)$ and the threshold value. The function related to Figure 2 is shown in Equation (11): 


$$
\phi_{i j, t}=e^{0.6459\left(\ln \frac{A_{j, t-1}}{A_{j, t-1}}-1.0678\right)^{2}}
$$

The empirical results for the threshold value show that the curve representing the relationship between technology transfers and technology distance for China is a U-shaped curve: hence it is different from the standard inverted curve we give in hypothesis 4 . This means that when technology distance is on the left side of the threshold, the effect of technology transfers declines as technology distance increases. Cross regional technology transfers occur mostly between provinces that are at a similar stage of technological progress. With regard to right side of the threshold, since the threshold is outside the range of estimated technology distance based on our provincial samples, it is impossible to observe any turning trend on the right side of the threshold currently.

Observing the area specific results from the basic models in Table 4, we find that $\rho$ is significant for the combined centre and west area, but not for the eastern region. It can therefore be deduced that cross regional technology transfer pattern, as shown in figure 2, are more relevant in the case of the former than in the latter. Hence, it can be argued that cross regional technology transfers significantly take place in backward areas, and that these transfers are faster in regions that are technologically close to the technology frontier. Technological catch-up through domestic factors appears to be possible for backward areas, a result which implies the possibility of convergence among Chinese regions.

The underlying cause of the U-shaped relationship may be the opposing effects of positive transfer and negative crowding-out effects. We can illustrate this point if we move from right 
to left along the $\mathrm{X}$ axis in Figure 2, noting that when the technology distance between regions is large and on the right side of the threshold, the dominant effect is technology transfer rather than crowding-out. As the technologically backward areas catch up and technology distances become closer to the threshold, products of the advanced and backward regions become similar and competition among them intensifies. Furthermore, firms in advanced areas will pay more attention to preventing their technologies from leaking out to rivals. Competition then causes crowding-out effects that slow down technology transfer. However, a turning point exists where this trend changes. Where technologies continue to improve in the less advanced areas, they build up a technological foundation which helps them to overcome the negative crowding-out effects. Their absorptive capacities improve and the technological protection of advanced regions becomes less efficient. Our empirical results show that, among the less advanced regions, all of them have already reached the left side of the turning point and are no longer negatively dominated by cross regional crowding-out effects. According to the relationship along the left side of the $U$ curve, the best way to smooth the cross regional technology transfers is to reduce the technology distance or to build transitional areas between the technologically advanced and backward areas, instead of increasing their technology distance.

\section{Independent impacts of $R \& D$ and learning by doing}

In Table 1, the coefficients of capital stock and R\&D stock are significant and positive for the three models, which shows that R\&D and learning by doing have a beneficial impact on 
China's technological progress. The coefficients of capital stock $(0.1689-0.1723)$ are bigger than those of R\&D stock (0.0693 - 0.1494). This suggests that learning by doing contributes more than R\&D does for Chinese technology progress during the study period. Since learning by doing is the technological progress route that is based on the accumulation of production experiences, it usually becomes a mechanism of 'imitation and arbitrage' and contributes little to independent innovation (CASS, 2006). This also implies that Chinese industries, featured as manufacturing factories for the world, lack independent innovative abilities .

The significant coefficients of learning by doing and R\&D in most models in Tables 1 and 2 illustrate that even though exterior technology transfer exists, domestic factors still play an important part in the technological progress of the country or region. Comparing the results of the East and the Central and West regions in the basic models of Table 2, we find that the coefficient of learning by doing for the combined centre and west region (0.2143) is greater than that for the east area $(0.134)$, and also greater than the coefficient of R\&D of the combined centre and west region (0.1069), which means that the west and centre part of China depend more on learning by doing to achieve technology progress.

In contrast, the coefficient of $R \& D$ of east area $(0.1525)$ is bigger than that of combined centre and west region (0.1069), and bigger than the coefficient of learning by doing of east area. Thus, for the same input of $\mathrm{R} \& \mathrm{D}$, the technologically advanced provinces get higher returns than the backward ones do, and the technology progress of the east area relies more on R\&D. This is a significant trend toward independent innovation, and it takes place firstly in the east coast of China. 


\section{Independent effects of FDI on technology progress}

In all three basic model results observed in Tables 3 and 4 , the coefficients of FDI are all negative, which shows that an increment in FDI does not cause technological progress by itself. This estimation result contradicts an important assumption about FDI and demonstrates that its direct impact is through crowding-out effects. There can be several explanations for this outcome. First, the absorption of FDI technology may need a certain technological foundation, including the $\mathrm{R} \& \mathrm{D}$ and learning by doing abilities cultivated by former practices. Therefore, the positive impacts of FDI are mainly reflected in the interaction items of FDI and domestic factors.

Second, it should also be pointed out that the most important beneficial aspect of FDI has to do with its existence, rather than with its quantity. For example, a small amount of FDI products can inspire innovation by local companies, while too much FDI may lead to a monopoly and can have crowding-out effects. On this line of thinking, Zhao and Zhang (2006), for instance, argue that the reason for the decreasing and vanishing FDI technology transfer effects is, in fact, excessive FDI. Recent research argues that the relationship between competition and productivity of firms is non-linear (Aghion, et al., 2005). There is an optimal level of competition. Therefore, the competition effect of FDI is also likely to be non-linear. A systematic investigation on this relationship is necessary for future research. 


\section{$R \& D$, learning by doing and their absorptive capacity}

As has been already noted, the above analysis resulted in negative coefficients for FDI. However, the coefficients of the interaction terms of FDI and R\&D are significantly positive in the R\&D interaction model of the east area shown in Tables 4. In relation to such estimations, we argue that the influence of $R \& D$ can be separated into independent innovative effects and absorptive abilities. The significant coefficients of R\&D itself, and of its interaction terms, demonstrate the existence of these two aspects. Thus, we can conclude that $\mathrm{R} \& \mathrm{D}$ is the foundation for FDI technology transfer because technology transfer of FDI usually occurs through intensive competition in native markets and upstream or downstream association. No core technology is transferred directly through these channels. Consequently, in order to acquire core technologies, it is imperative for a country to carry out independent R\&D activities, and make it reach a certain level as the east region does to propel the technology transfer from FDI.

Compared to the only pronounced capacity of R\&D to absorb FDI technological transfer in east part, its absorptive capacity vis-à-vis cross regional technology transfers is significant both in all regions (Table 3) and in east China (Table 4), and unfortunately, still insignificant in combined centre and west region. Similarly, the absorptive capacity of learning by doing for cross regional technology transfer is significant both in all regions and in east China. This suggests that native technologies from advanced region, which are more appropriate for the less advanced areas, are easier for domestically transferred, either through $R \& D$ or learning 
by doing. These native technologies may contain foreign technologies that have already been absorbed by the advanced regions.

As we already noticed the significance in the whole county and the insignificance in the combined east and west, a transit region, which covers part of east region and part of combined centre and west region, should exist between the technology frontier and the backward region, taking in account that the observation number of the east part alone is not enough to change the significant level of the whole country. We call this transit region the less advanced region. Another feature of this transit region is that they are prone to be in the left side of the curve in figure 2 , that is, be technologically close to the frontier and get high degree of technology transfer. Therefore, combining the above results of this model, a link can be created to transfer the technology from the advanced region to backward region. First, Technologies from FDI are absorbed by advanced area through the absorptive capacity of R\&D. Second, technologies from advanced region are transferred to less advanced regions by $\mathrm{R} \& \mathrm{D}$ or learning by doing. Third, technologies from less advanced region are transferred to backward regions directly, which does not significantly require the absorptive capacity of R\&D or learning by doing.

Although learning by doing is one of the major ways of gaining new technology, it is completely different to $\mathrm{R} \& \mathrm{D}$ in terms of the assimilation of technology transfers. This is because learning by doing appears to perform better in absorbing cross regional technology transfers than FDI technology transfer, as can be observed from our results. This implies that learning by doing contributes little to the absorption of FDI technology, yet plays an 
important role in absorbing cross regional transferred technology. The major function of learning by doing is to help new technology to mature. This mechanism is not favourable for FDI technology transfer, given the fact that FDI core technologies are complex. However, the situation is different in the case of cross regional technology transfers because technology distance among regions is not as significant and the technologies of the advanced areas are appropriate for those that fall behind. This explains that why the coefficient of the interaction term of learning by doing and technology distance $(0.1416)$ is greater than that of the interaction of R\&D and technology distance (0.082) in Table 3.

Hence, transit region is very import in the procedure of technology progress of China, by strengthening R\&D activities and learning by doing, can benefit from the effects associated with the 'two aspects of R\&D and learning by doing' (independent contribution and absorptive capacity) and absorbed technologies transferred from advanced regions which may include assimilated FDI technology, that is, 'bi-channel technology transfer' (international and intra-national technology transfers.

\section{A comparison between international and intra-national technology transfers}

FDI technology transfer is only significant in the east region and via the apsorptive capacity of $\mathrm{R} \& \mathrm{D}$, and the coefficients for FDI considered separately from the interaction term are significantly negative. That is, apart from the interaction item, FDI does not impact directly on technological progress and requires a high absorptive capacity of $R \& D$ to assimilate its technology. Compared to this, the coefficients of the interregional technology distance term 
and its square considered separately from the interaction term, that is, $\rho$ and $\varphi$, are significant in all the models of Table 3 and in most models of Table 4. This means that interregional technology transfer has a direct impact and becomes stronger when technology distance decreases. Second, native technology transfers can be absorbed via learning by doing, in addition to $\mathrm{R} \& \mathrm{D}$. These empirical results point to the fact that interregional technology transfer is more extensive and contributes more to the technological development of different regions in China than technology transfers via FDI.

There can be several reasons why the cross regional technology transfers are the stronger aspect of bi-channel technology transfer. First, technologies transferred from other advanced native areas are more appropriate to the conditions of another region in the same countries and thereby easier to be assimilated by firms in those regions, while FDI technology can be too complex and inappropriate. Second, transferred technology should fit with the local factor endowment. According to the appropriate technology theory (Bash and Weil, 1998; Lin and Zhang, 2005), some technology developed in the advanced countries is suitable only for the factor endowment structure of such nations. Therefore, in order to achieve valid transfers, in adapting these technologies, developing countries should pay attention to technology that is adequate for their own factor endowment. In this respect, and compared to foreign technology, transfers from the technologically advanced domestic areas may be more appropriate for the local factor endowment.

Third, the exchange of human resources is more frequent, and the connection based on intermediate products is closer, among native companies than that established with foreign 
enterprises. An investigation carried out by Wu (1995) shows that only 29.4 per cent of foreign-funded firms in China provided technology spillover effects. This result is similar to the crowding-out effects of our non-interaction FDI term. Also, research by Yao and Zhang (2001) finds that within a specific industry, state-owned enterprises have significant technology transfer effects but foreign-funded enterprises do not. Consequently, informal transfers of technology, such as interpersonal contacts or informal networks of friends and part time employees, are more important for technologically backward areas or firms, and these usually occur within native sectors. Close relationships between domestic enterprises within the same industry make the interregional element more important.

\section{Conclusions}

This paper has analysed the role of $\mathrm{R} \& \mathrm{D}$, learning by doing, FDI and cross regional technology transfer in regional technological development in China. The results show that cross regional technology transfer is more important than international technology transfers. $\mathrm{R} \& \mathrm{D}$ is found to play a crucial role in the assimilation of international technology transferred through FDI in advanced region and the absorption of intra-national technology transfer in transit region, whereas learning by doing is important for the absorption of intra-national transfer of indigenous technology in transit region. The effect of FDI is negative if there is no interaction with indigenous $\mathrm{R} \& \mathrm{D}$ for assimilation and adaptation. By contrast, cross regional technology transfers can generate direct positive effects. 
Evidence from this study indicates the existence of cross regional technological transfers and the importance of a threshold of absorptive capacity. It suggests a downward slope relationship between technology transfer and technology distance. It suggests that the closer the technology distance is, the easier it becomes for technology transfer to be effective. Hence, a transit region, which is close to the technology frontier and can aborted technology from advanced region, is the crucial link to transfer along the terraced structure from technology peaks to technology valleys.

Actually, the significant impacts of technology distance indicate technology convergence amongst Chinese regions. For the technologically backward regions, learning by doing and $\mathrm{R} \& \mathrm{D}$, especially learning by doing are key internal impetus to secure the technology progress. Cross regional technology transfers are mainly take place in directly methods in these regions. It probably implies that these technologies are not so complicated that they do not need the help from absorptive capacity.. For regions that have already achieved an advanced level of technology, learning by doing, R\&D, and FDI technology transfer based on $\mathrm{R} \& \mathrm{D}$ also have a positive impact on local technological progress.

Therefore, strategies to achieve technological progress should be differentiated across regions. Foreign technology and independent innovations should be given priority in the technologically advanced areas. For developing countries with limited budget, it is economically efficient to support R\&D in advanced areas. Moreover, these regions normally attract substantial amounts of FDI. The level of FDI should be such that it is sustainable for 
domestic firms to compete, and appropriate for the absorptive capacity existing within the region. The latter can be enhanced in the local economy through $\mathrm{R} \& \mathrm{D}$ and learning by doing.

Policy measures should be taken to narrow the technology distance between domestic regions and expand the area of transition, so as to facilitate the inter-regional technology transfer. Cross regional technology transfer is more important than international transfers for the backward areas, where the techniques embedded in FDI might not be suitable. Moreover, advanced indigenous technology is more suitable for the less advanced regions, and technology transfer less restrictive. 


\section{References}

Acemoglu, D., (2002), Directed Technical Change, Review of Economic Studies, 69(4), pp. 781-810.

Aghion, P., N. Bloom, R. Blundell, R. Griffith, and P. Howitt, 2005. Competition and Innovation: An Inverted U Relationship, Quarterly Journal of Economics, v. 120, v 2, 701-728.

Aitken, B. J., and Harrison, A. E. (1999) Do Domestic Firms Benefit from Direct Foreign Investment? Evidence from Venezuela, American Economic Review, 89 (3), pp. 605-18.

Atkinson A.B. and Stiglitz J.E., (1969) A new view of technological change, Economic Journal 79, pp. 573- 578.

Arrow, K. J. (1962) The Economic Implications of Learning by Doing, The Review of Economic Studies, 29 (2), pp. 155-73.

Bahk, B.-H., and Gort, M. (1993) Decomposing Learning by Doing in New Plants, Journal of Political Economy, 101 (4), pp. 561-83.

Barro, R., and Sala-i-Martin, X. (1995) Economic Growth (New York: McGraw Hill), pp. 186-94.

Bash, S., and Weil, D. (1998) Appropriate Technology and Growth, The Quarterly Journal of Economics, 113 (4), pp. 1025-54.

Borensztein, E., Gregorio, J. D. and Lee, J. W. (1995) How Does Foreign Direct Investment Affect Economic Growth?', NBER Working Paper 5057 (Cambridge, MA: National Bureau of Economic Research).

Brendstetter, L. G. (2001) Are Knowledge Spillovers International or Intra-national in Scope? Microeconometric Evidence from the US and Japan. Journal of International Economics, 53 (1), pp. 53-79.

Cameron, G., Proudman, J. and Redding, S. (2005) Technological convergence, R\&D, trade and productivity growth, European Economic Review, 49, 775 - 807.

Caniëls, M. C. J., and Verspagen, B. (1999) The Effects of Economic Integration on Regional Growth: an Evolutionary Model. ESRA conference papers, ersa99pa219. (Liverpool: European Regional Science Association).

CASS (Research Group of the Economic Institute of CASS) (2006) Learning by Doing, Low Cost Competition and Conversion of Economic Growth Patterns, (China) Economic Research, (4), pp. 4-14.

Eden, L., Lecitas, E. and Martinez, R. J. (1997) The Production, Transfer and Spillover of Technology: Comparing Large and Small Multinationals as Technology Producers, Small Business Economics, 9 (1), pp.53-66.

Erdilek, A. (1984) International Technology Spillovers in the Middle East and North Africa, Management Decision, 22 (2), pp. 45-9.

Fagerberg, J. (1994) Technology and International Differences in Growth Rates, Journal of Economic Literature, 32(3), pp. 1147-75.

Findlay, R. (1978) Relative Backwardness, Direct Foreign Investment and the Transfer of Technology: A Simple Dynamic Model, Quarterly Journal of Economics, 92 (1), pp. 1-16. 
Fu, X. (2008) Foreign Direct Investment, Absorptive Capacity and Regional Innovation Capabilities: Evidence from China, Oxford Development Studies, 36 (1), pp. 89-110.

$\mathrm{Fu}, \mathrm{X}$. and Gong, Y. (2011) Indigenous and foreign innovation efforts and drivers of technological upgrading in China, World Development, V37, no 5.

Girma, S. (2005) Absorptive Capacity and Productivity Spillovers from FDI: A Threshold Regression Analysis, Oxford Bulletin of Economics and Statistics, 67 (3), pp. 281-306.

Griffith, R., Redding, S. and Reenen, J .V. (2004) Mapping the two Faces of R\&D: Productivity Growth in a Panel of OECD Industries. The Review of Economics and Statistics, 86 (4), pp. 883-95.

Griliches, Z. (1980) R\&D and Productivity Slowdown. American Economic Review, 70 (2), pp. 343-8.

Griliches, Z. (1990) Patent statistics as economic indicators: A survey. Journal of Economic Literature, Dec., 28 (4), pp.1661-1707.

Hoekman, B. M., Maskus, K. E, and Saggi, K. (2004) Transfer of Technology to Developing Countries: Unilateral and Multilateral Policy Options. WB Policy Research Working Paper 3332 (Washington, DC: World Bank).

Ivarsson, I. (2002) Transnational corporations and the geographical transfer of localised technology: a multi-industry study of foreign affiliates in Sweden, Journal of Economic Geography, 2, 221-247.

Jovanovic.B ,1995, "Learning and Growth”, NBER Working Paper , 5383.

Kinoshita, Y. (2001) R\&D and technology spillovers through FDI: innovation and absorptive capacity. CEPR Discussion Paper 2775.

Kokko, A., Tansini, R. and Zejan, M. (1997) Trade Regimes and Spillover Effects of FDI: Evidence from Uruguay (Stockholm: Stockholm School of Economics. Unpublished manuscript).

Lall, S. (2004) Industrial Success and Failure in a Globalizing World. Journal of Technology Management and Sustainable Development, 3 (3), pp. 189-213.

Li, X. and Z. Zhu (2006) International Trade, R\&D Spillover and Productivity Development: Based on the Analysis of Chinese Industry's Panel data, (China) Economic Research, 2, pp. 31-43.

Lin, Y. and P. Zhang (2005) Appropriate Technology, Technical Selection and the Economic Growth of Developing County's Techniques. CCER Working Paper, 2005-004 (Beijing: China Center for Economic Research, Peking University).

Mansfield, E. (1985) How Rapidly Does New Industrial Technology Leak Out?, Journal of Industrial Economics, 34 (2), pp.217-23.

Nadiri,M.I. (1980) Contributions and developments of research and development expenditures in the U.S. manufacturing industries, in G.M.Furstenburg (eds), Capital Efficiency and Growth ( Cambridge,MA: Ballinger).

NBS (National Bureau of Statistics) (various issues) China Statistical Yearbooks (Beijing: Statistical Press).

NBS (various issues) China Statistical Yearbooks on Science and Technology (Beijing: Statistical Press). 
OECD (Organization for Economic Cooperation and Development) (2002) Science and Technology Industry Outlook (Paris: OECD).

Potter, P., Moore, B. and Spires, R. (2002) The wider effects of inward foreign direct investment in manufacturing on UK industry, Journal of Economic Geography, 2, 279-310.

Romer, P. M. (1990) Endogenous Technological Change, Journal of Political Economy, 98 (5), pp. S71-S102.

Wu, N. (1995) Performance Analysis of Guangdong Overseas Chinese, Joint Ventures and Foreign Enterprises (Guangzhou: Sun Yat-sen University Press).

Yao, Y., and Q. Zhang (2001) An Analysis of Technological Efficiency of Chinese Industrial Firms, (China) Economic Research, 10, pp. 13-28

Young, A. (1993) Invention and Bounded Learning by Doing, The Journal of Political Economy, 101 (3), pp. 443-72.

Zhang, J., and Shi, S. (2003) Change of Total Factor Productivity in the Chinese Economy: 1952-1998, (China) World Economic Forum, (2), pp. 17-24.

Zhang, J., Wu, G. and Zhang, J. (2004) The Estimation of China's Provincial Capital Stock: 1952 -2000, (China) Economic Research, (10), pp.35-44.

Zhao, Q., and C. Zhang (2006) Economy Growth and Technology Spillover Effects of FDI: the Case of Jingjinji Area, (China) Journal of Quantitative \& Technical Economics, (3), pp. 11-20. 
Figure 1. Comparison of total factor productivity of east, central and west regions of China

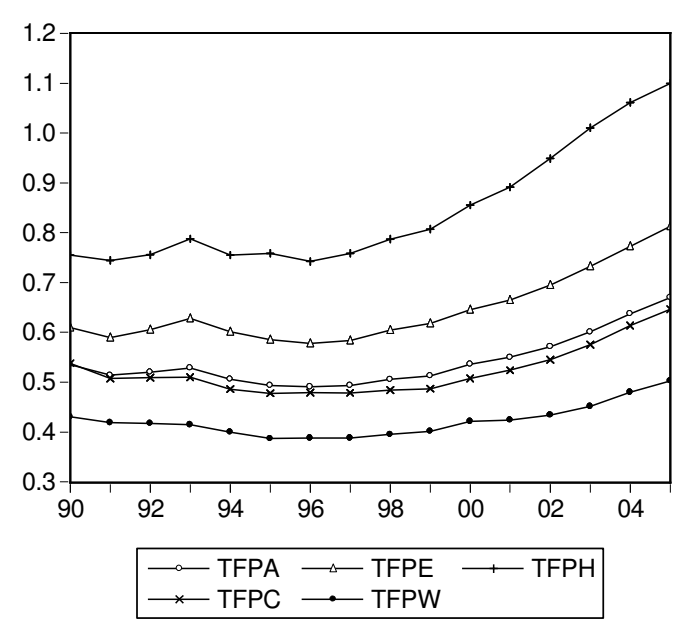

(a) Average TFP of the regions.

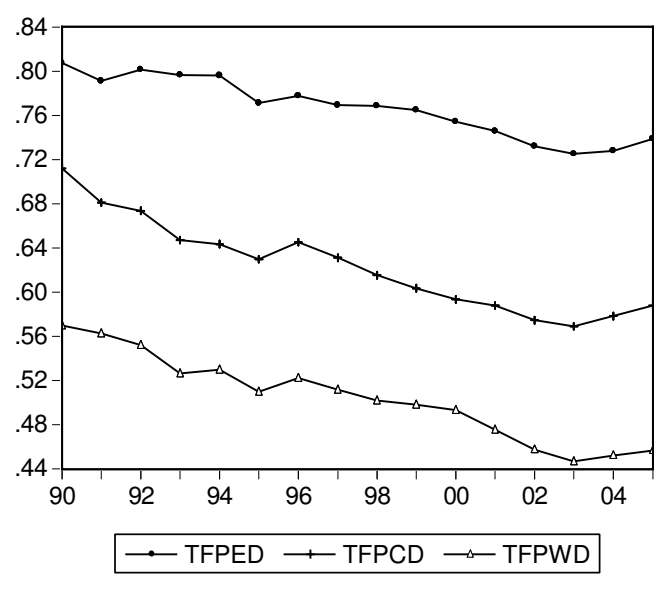

(b) TFP distance to the frontier

Source: Generated by authors, based on estimations described in the paper. 
Figure 2. Estimated curve of the relationship between technology spillovers and technology distance

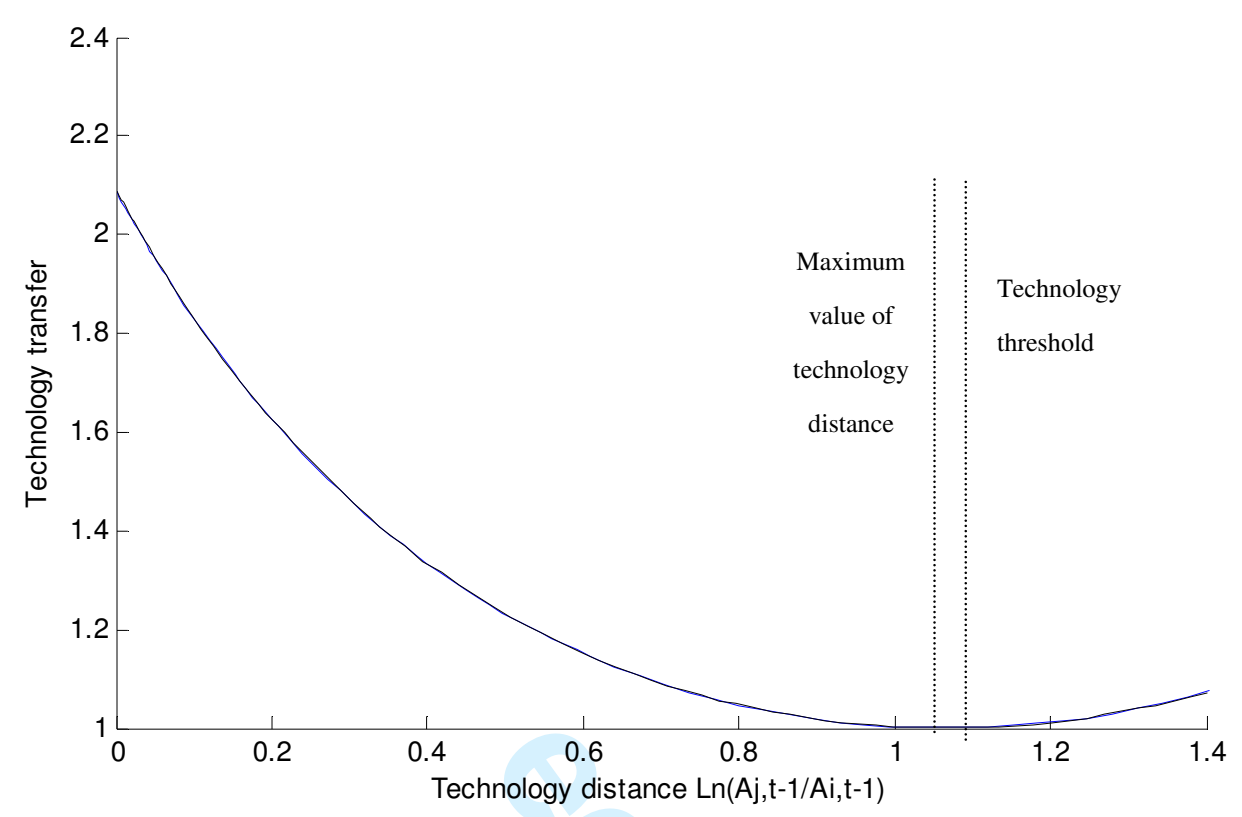

Source: Figure computed by authors based on Equation (11). 
Table 1 Provincial and Regional TFP averages of all years

\begin{tabular}{llllll}
\hline Province & TFP & Province & TFP & Province & TFP \\
\hline Beijing & 0.6212 & Shanxi & 0.5275 & Sichuan & 0.3550 \\
Tianjin & 0.6275 & Neimenggu & 0.5231 & Guizhou & 0.3559 \\
Hebei & 0.6264 & Jilin & 0.6297 & Yunnan & 0.4624 \\
Liaoning & 0.7505 & Heilongjiang & 0.5991 & Shaanxi & 0.4379 \\
Shanghai & 0.7116 & Anhui & 0.4601 & Gansu & 0.4603 \\
Jiangsu & 0.6470 & Jiangxi & 0.5189 & Qinghai & 0.3740 \\
Zhejiang & 0.6191 & Henan & 0.5108 & Ningxia & 0.3974 \\
Fujian & 0.6611 & Hubei & 0.5127 & Xinjiang & 0.4976 \\
Shandong & 0.6117 & Hunan & 0.5230 & West & 0.4176 \\
Guangdong & 0.8613 & Guangxi & 0.5028 & & \\
Hainan & 0.4842 & Central & 0.5308 & & \\
East & 0.6565 & & & Total & 0.5472 \\
\hline
\end{tabular}


Table 2. Descriptive statistics of variables

\begin{tabular}{l|rrrr}
\hline & Mean & Maximum & Minimum & Std. Dev. \\
\hline TFP & 0.547 & 1.121 & 0.295 & 0.139 \\
$K$ & 3342.938 & 21305.810 & 153.304 & 3468.771 \\
R\&D & 144.590 & 1361.124 & 1.254 & 194.393 \\
STOCK & & & & \\
FDI STOCK & 284.251 & 3550.735 & 0.000 & 546.548 \\
\hline
\end{tabular}

Notes: Pecuniary values are given in 1990 constant prices. 
Table 3. Estimated results for technology spillover models

\begin{tabular}{|c|c|c|c|c|c|c|}
\hline & \multicolumn{2}{|l|}{ Base model } & \multicolumn{2}{|c|}{$R \& D$ interaction model } & \multicolumn{2}{|c|}{$\begin{array}{l}\text { Learning by doing } \\
\text { interaction model }\end{array}$} \\
\hline & Coefficient & t statistic & Coefficient & t statistic & Coefficient & t statistic \\
\hline $\mathrm{C}$ & $-1.7866 * * *$ & -18.0763 & $-1.6343 * * *$ & -13.6922 & $-1.8944 * * *$ & -11.374 \\
\hline $\ln \left(\mathrm{K}_{\mathrm{i}, \mathrm{t}}\right)$ & $0.1679 * * *$ & 7.2273 & $0.1689 * * *$ & 7.3143 & $0.1723 * * *$ & 6.2824 \\
\hline $\operatorname{Ln}\left(\mathrm{R}_{\mathrm{i}, \mathrm{t}-1}\right)$ & $0.1078 * * *$ & 6.0763 & $0.0693 * * *$ & 2.9206 & $0.1494 * * *$ & 8.0856 \\
\hline $\ln \left(\mathrm{F}_{\mathrm{i}, \mathrm{t}-1}\right)$ & $-0.0287 * * *$ & -6.0098 & $-0.0294 * * *$ & -3.846 & $0.0437 * * *$ & 3.4193 \\
\hline $\operatorname{Ln}\left(\mathrm{R}_{\mathrm{i}, \mathrm{t}-1}\right) \bullet \ln \left(\mathrm{F}_{\mathrm{i}, \mathrm{t}-1}\right)$ & & & 0.0007 & 0.3599 & & \\
\hline $\ln \left(\mathrm{K}_{\mathrm{i}, \mathrm{t}}\right) \cdot \ln \left(\mathrm{F}_{\mathrm{i}, \mathrm{t}-1}\right)$ & & & & & $-0.0124 * * *$ & -5.8107 \\
\hline $\ln \left(\mathrm{A}_{\mathrm{j}, \mathrm{t}-1} / \mathrm{A}_{\mathrm{i}, \mathrm{t}-1}\right)$ & $-1.3794 * * *$ & -12.9088 & $-1.6955 * * *$ & -11.8828 & $-2.207 * * *$ & -10.046 \\
\hline $\ln ^{2}\left(A_{j, t-1} / A_{i, t-1}\right)$ & $0.6459 * * *$ & 6.8783 & $0.5924 * * *$ & 6.2465 & $0.2981 * * *$ & 3.0027 \\
\hline $\operatorname{Ln}\left(\mathrm{R}_{\mathrm{i}, \mathrm{t}-1}\right)_{1} \bullet \ln \left(\mathrm{A}_{\mathrm{j}, \mathrm{t}-1} / \mathrm{A}_{\mathrm{i}, \mathrm{t}-1}\right)$ & & & $0.082 * * *$ & 3.3053 & & \\
\hline $\ln \left(\mathrm{K}_{\mathrm{i}, \mathrm{t}}\right) \cdot \ln \left(\mathrm{A}_{\mathrm{j}, \mathrm{t}-\mathrm{l}} / \mathrm{A}_{\mathrm{i}, \mathrm{t}-1}\right)$ & & & & & $0.1416 * * *$ & 4.7601 \\
\hline Adjusted $\mathrm{R}^{2}$ & 0.920 & & 0.922 & & 0.931 & \\
\hline F statistic & 162.482 & & 156.689 & & 178.278 & \\
\hline
\end{tabular}

Note: Dependent variable is $\ln \left(\mathrm{A}_{\mathrm{i}, \mathrm{t}}\right)$.

* Significant at $10 \%$ level. ** Significant at 5\% level. *** Significant at $1 \%$ level. 
Table 4. Estimated results for technology spillovers models (Separated into east area and combined central and west area)

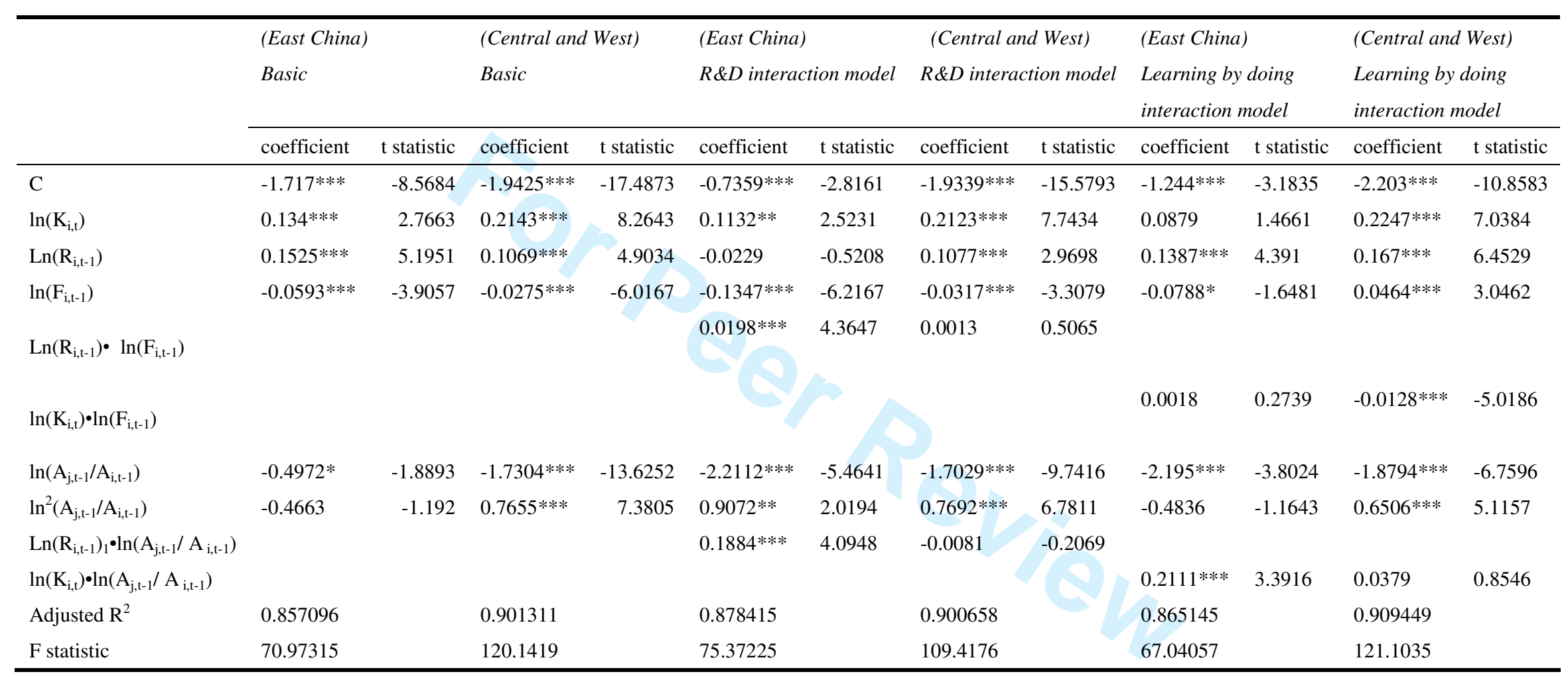

Note: Dependent variable is $\ln \left(\mathrm{A}_{\mathrm{i}, \mathrm{t}}\right)$.

* Significant at $10 \%$ level. ** Significant at 5\% level. *** Significant at $1 \%$ level. 